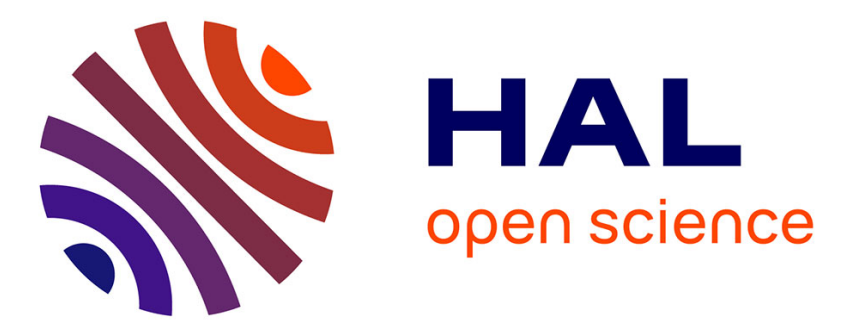

\title{
Assessing complementarity in organizational innovations for technological innovation: the role of knowledge management practices
}

\author{
Caroline Mothe, Uyen T. Nguyen-Thi, Phu Nguyen Van
}

\section{To cite this version:}

Caroline Mothe, Uyen T. Nguyen-Thi, Phu Nguyen Van. Assessing complementarity in organizational innovations for technological innovation: the role of knowledge management practices. Applied Economics, 2015, 47 (29), pp.3040-30588. 10.1080/00036846.2015.1011320 . hal-01293882

HAL Id: hal-01293882

https://hal.univ-grenoble-alpes.fr/hal-01293882

Submitted on 12 Apr 2016

HAL is a multi-disciplinary open access archive for the deposit and dissemination of scientific research documents, whether they are published or not. The documents may come from teaching and research institutions in France or abroad, or from public or private research centers.
L'archive ouverte pluridisciplinaire HAL, est destinée au dépôt et à la diffusion de documents scientifiques de niveau recherche, publiés ou non, émanant des établissements d'enseignement et de recherche français ou étrangers, des laboratoires publics ou privés.

\section{(c)(1)}

Distributed under a Creative Commons Attribution| 4.0 International License 
Assessing complementarity in organizational innovations for technological innovation: the role of knowledge management practices

\author{
Caroline Mothe ${ }^{\mathrm{a}}$, Uyen T. Nguyen-Thi ${ }^{\mathrm{b}}$, and Phu Nguyen-Van ${ }^{\text {cd* }}$ \\ ${ }^{a}$ IREGE, University of Savoie, France \\ ${ }^{b}$ CEPS/INSTEAD, Luxembourg \\ ${ }^{c}$ BETA-CNRS, University of Strasbourg, France \\ ${ }^{d}$ IPAG Business School, France
}
*Corresponding author. Phu Nguyen-Van, BETA-CNRS, Université de Strasbourg, 61 avenue de la Forêt Noire, F-67085 Strasbourg Cedex, France ; Phone: +33 (0)3 68852039 ; Fax: +33 (0)3 68852070 ; E-mail: nguyen-van@unistra.fr




\title{
Assessing complementarity in organizational innovations for technological innovation: the role of knowledge management practices
}

\begin{abstract}
We here empirically investigate the pattern of complementarity between four organizational practices. Firm-level data were drawn from the Community Innovation Survey (CIS) carried out in 2008 in Luxembourg. Supermodularity tests confirm the crucial role of organizational innovation in raising firms' technological innovation. The pattern of complementarity between organizational practices differs according to the type of innovation, i.e. product or process innovation, but also according to whether the firm is in the first stage of the innovation process (i.e. being innovative or not) or in a later stage (i.e. innovation performance in terms of sales of new products).
\end{abstract}

Keywords: Complementarity; Organizational innovation; Substitution; Supermodularity; Technological innovation 


\section{Introduction}

Empirical works have given limited attention to other innovation strategies such as those implemented in non-technological fields. Organizational innovation is seen as "the implementation of a new organizational method in the firm's business practices, knowledge management, workplace organization or external relations that has not been previously used by the firm" (OECD, 2005). We here retained these four types of organizational innovation practices. Firms introducing both technological and organizational innovations have a clear competitive advantage with respect to both non-innovating firms and to firms that adopt a narrow approach to innovation (e.g. Miravete and Pernias, 2006; Evangelista and Vezzani, 2010; Günday et al., 2011).

Some empirical studies have acknowledged the existence of synergistic effects that may arise as the result of the simultaneous adoption of complementary organizational practices, showing however controversial results (Ichniowski et al., 1997; Cappelli and Newmark, 2001). Although the recent literature has substantially improved our understanding of such complementarities, the types of organizational practices analyzed have been mainly limited to new workplace organization (Ichniowski et al., 1997; Cappelli and Newmark, 2001), human resource management practices (Laursen and Mahnke, 2001) and external relations (Arora and Gambardella, 1990). Other forms of organizational innovation such as outsourcing, partnership, sub-contracting and business work practices (quality management, reengineering, lean management, etc.) have not received sufficient attention. Hence, such alternative organizational practices have not been studied together.

We here highlight the differences of complementary/substitution effects for product/process innovation on one hand and for the two stages of the innovation process on the other hand. This is of considerable importance as it could suggest that technological innovation performance could be improved if certain types of organizational innovation practices were also implemented and combined. Moreover, although the crucial role played by organizational practices for technological innovation has long been acknowledged, studies addressing the effects of complementarity on innovation performance not only remain scarce, but also focus mainly on sub-practices within groups of organizational strategies (such as external R\&D relationships or work practices). A broader analysis on the complementary effects of organizational innovation practices on technological innovation performance had not been undertaken yet.

The notion of complementarity characterizes the beneficial interplay of the design 
elements of a system in which doing more of one thing increases the returns from doing more of the other (Milgrom and Roberts, 1990, 1995). Several studies have investigated the complementarities between internal $\mathrm{R} \& \mathrm{D}$ expenditures and external technology sourcing (e.g. Audretsch et al., 1996; Love and Roper, 2001; Cassiman and Veugelers, 2006; Belderbos et al., 2006; Schmiedeberg, 2008), process and product innovations (Miravete and Pernias, 2006; Polder et al., 2010), or different obstacles to innovation (Mohnen and Röller, 2005; Galia and Legros, 2004).

Research in the fields of industrial organization, strategic management and innovation has long been interested in investigating the possible complementary relations between firms' various organizational practices. Sets of strategic activities could lead to a sustainable competitive advantage and strategies can act as substitutes or complements to one another. This notion was further developed by the study of supermodularity on lattices and in a formal model of complementarity (Migrom and Roberts, 1995; Topkis, 1998). Supermodularity is the mathematical equivalent to the idea that the gain achieved from increasing all components is higher than the sum of gains obtained from the separate individual increases (Milgrom and Roberts, 1990). The mathematical tools of lattice theory have thus been applied in the economics and management fields to develop models of this so-called Edgeworth complementarity. The implementation of one practice increases the marginal or incremental return of other practices. By the same token, the implementation of one practice may decrease the marginal or incremental return of other practices: these practices are "substitutable". Milgrom and Roberts (1990, 1995) suggested that adopting a new organizational practice will only generate improved firm performance if it is in line with the firm's other choices. The supermodularity theory emphasizes organizational and strategic factors and proposes a simple model to explain the move from Fordist firms based on mass production to "modern" lean and flexible firms with "modern" organizational practices. Supermodularities (or complementarities) within modern manufacturing firms will lead to higher profits. Moreover, it suggests that firms will have no interest in adopting a given organizational practice if they have not undergone a thorough overhaul of their entire organizational design.

Recent empirical studies of organizational performance have focused on establishing potential complementarities between more than two organizational practices adopted simultaneously (see Carree et al., 2011, for a review). However, empirical research on complementarities between different innovation strategies remains scarce. In this paper, we consider the relationship of four organizational practices (business practices, knowledge 
management, workplace organization and external relations) and their synergistic effect on technological innovation throughout the innovation process. Our underlying hypothesis is that firms are faced with the challenge of organizing innovation processes in a holistic fashion as strategic organizational activities are interrelated and may thus generate a competitive advantage thanks to a better exploitation of synergies among existing resources. Indeed, the firm's capacity to simultaneously combine strategic organizational activities is a crucial determinant of innovation performance. These can lead to sustained performance differences among firms due to subsequent creation of specific and unique skills within the firm as well as to difficulties in imitating organizational capabilities (Teece, 1986).

In line with these key findings, we here investigate in further detail the relationships between organizational and technological innovation, focusing on organizational innovation practices' complementarities and on their impact on technological innovation. We thus aim to identify which organizational strategies are complements or substitutes for shaping subsequent product and/or process innovation as well as product innovative performance. Studying the effect of complementarities between organizational practices on innovation performance is of particular interest as it suggests that this performance can only be improved and become more effective if all organizational innovation practices are also implemented (or certain combinations among them). As complementarities lead to synergies among the complementary activities; failing to take them into account may entail a loss in value creation and performance - as the firm fails to achieve its full potential.

The remainder of the article is organized as follows: Section II highlights the role of organizational innovation in technological innovation processes and provides an overview on complementarities in organizational practices. Section 3 describes the dataset from the Luxembourg CIS 2006 and the variables used. Section 4 introduces the methodology used for testing complementarities. Estimation results are presented and discussed in Section 5. Section 6 concludes the study.

\section{Methodology for testing complementarities}

The concept of complementarity refers to the presence of systems effects and synergies of alternative activities and has been widely used to study innovation processes. Organizational practices are complements if their simultaneous implementation pays off more than the isolated adoption of each of them. We analyze the contribution of different combinations of practices directly on firm innovation performance. The analysis (also known as 'performance' 
approach) is based directly on the objective function of the firm. ${ }^{1}$ The main idea is that simultaneous implementation of different activities should prove to be more valuable than implementing each of them separately. The test of complementarity is thus performed by regressing a measure of firm performance on a set of interaction terms between the considered activities, interpreted as complementarity parameters. Comparing the impacts of alternative combinations of activities stemming from this estimation permits to identify complementarity effects between these activities. It is possible to obtain certain supportive evidence of complementarity (substitutability) when significant and positive (negative) coefficients are observed for the interaction terms. Formally, this approach can be traced back to supermodularity (Milgrom and Roberts, 1995; Topkis, 1998). The intuition is that whenever activities are complementary, the objective function is supermodular. Note that the related definition of supermodularity provided by Milgrom and Roberts (1995) only requires a nonnegative (rather than a positive) impact of one practice on the marginal returns of another practice.

Applying this approach, Mohnen and Röller (2005) estimated the innovation function directly and investigated whether policy decisions (i.e. obstacles to innovation that are affected by policies) were complementary. Lokshin et al. (2008) studied the complementarity between product, process and organizational innovations and their impact on labour productivity. Ichniowski et al. (1997) also used this approach to test the complementarity between different human resource management practices. With a sample of 36 homogeneous steel production lines, they found that using a set of innovative work practices such as teams, flexible job assignments or training led to higher output and product quality. This approach was also used by Cassiman and Veugelers (2006) to investigate complementary innovation activities (in-house R\&D, external technology sourcing, etc.) and their impact on firm performance.

In the present paper, we test for complementarity in innovation activity and innovation performance. We estimate the probability of observing a (product or process) innovation activity, and then the "innovation function" related to product innovation. These two estimations consider alternative combinations of organizational practices as explanatory variables. The analysis focuses directly on the relation between innovation performance and

\footnotetext{
${ }^{1}$ An alternative approach, known as the correlation or adoption analysis, is presented in Appendix B. However, it does not provide a sufficient condition to conclude that a possible complementarity relationship exists between different activities. This approach gives some suggestive evidence of complementarity between the four considered organizational practices. This evidence remains to be confirmed by the 'performance' approach.
} 
different practices of organizational innovation in order to compare the impact of alternative combinations of practices on firm innovation activity and performance.

We first considered firms' innovation activity and estimated the function that takes the following form:

$$
P_{i}^{*}=\sum_{j=0}^{15} S_{j} \gamma_{j}+X_{i}^{\prime} \alpha+\varepsilon_{i}
$$

where $P_{i}^{*}$ is the latent variable corresponding to the probability to innovate in product or process. According to the performance approach and similarly to Mohnen and Röller (2005), a set of state dummy variables $S_{j}$ was inserted into the model. As four organizational practices were considered, this set corresponds to sixteen dummy variables $50 \_0 \_0 \_0$, s0_0_0_1, ..., s1_1_1_1, where the four indices denote the four practices, respectively, i.e. business practices, knowledge management, workplace organization, and external relations. For each dummy $s k \_l \_m \_n$, the four indices $(k, l, m, n=0,1)$ represent the presence or absence of each of the four practices. For example, $s 1_{-} 0 \_1 \_0$ indicates that business practices and workplace organization are present while knowledge management and external relations are not. $X_{i}$ represents the set of explanatory variables, including controls for firm-level heterogeneity such as firm size, sectors of activities and foreign ownership as well as a set of variables that have previously been shown to be relevant determinants of innovation performance at the firm level, such as the intensity of internal and external R\&D and obstacles to innovation. As equation (1) applied to both product and process innovation, we used a biprobit model to estimate this equation for product and process innovations.

Concerning innovation performance, and following Mohnen and Röller (2005), we used the following model:

$$
I_{i}=\sum_{j=0}^{15} S_{j} \delta_{j}+W_{i}^{\prime} \beta+v_{i}
$$

where $I_{i}$ is the innovation performance of firm $i$, measured as the share in sales of innovative products (PERFOR). $W_{i}$ is the set of control variables, including firm size, sectors of activities, foreign ownership and obstacles to innovation. Note that this model only concerns product innovation as no similar information is available for process innovation. Moreover, since only 266 firms (out of 568) innovated in product, we used the Heckman's two-step 
selection model to control for selection bias related to product innovation activity. In this model, the second step corresponds to the performance equation given in (2) whereas the first-step corresponds to a probit estimation of the probability of having a product innovation (or the propensity to innovate) as given in (1).

Following this, we performed supermodularity and submodularity tests for complementarity and substitutability, respectively, in organizational practices. For innovation activity, these tests were based on consistent estimates of coefficients $\gamma_{j}$ (equation (1)). As in Mohnen and Röller (2005), complementarity between each pair of practices should satisfy the following constraints: ${ }^{2}$

$$
\begin{aligned}
& \text { (practices } 1 \text { and 2) } \gamma_{8+s}+\gamma_{4+s} \leq \gamma_{0+s}+\gamma_{12+s} \text { where } s=0,1,2,3, \\
& \text { (practices } 1 \text { and 3) } \gamma_{8+s}+\gamma_{2+s} \leq \gamma_{0+s}+\gamma_{10+s} \text { where } s=0,1,4,5, \\
& \text { (practices } 1 \text { and 4) } \gamma_{8+s}+\gamma_{1+s} \leq \gamma_{0+s}+\gamma_{9+s} \text { where } s=0,2,4,6, \\
& \text { (practices } 2 \text { and 3) } \gamma_{4+s}+\gamma_{2+s} \leq \gamma_{0+s}+\gamma_{6+s} \text { where } s=0,1,8,9, \\
& \text { (practices } 2 \text { and 4) } \gamma_{4+s}+\gamma_{1+s} \leq \gamma_{0+s}+\gamma_{5+s} \text { where } s=0,2,8,10, \\
& \text { (practices } 3 \text { and 4) } \gamma_{2+s}+\gamma_{1+s} \leq \gamma_{0+s}+\gamma_{3+s} \text { where } s=0,4,8,12 \text {. }
\end{aligned}
$$

The substitutability between each pair of practices should satisfy the analogous inequalities, which are however of opposite signs.

The hypotheses that pair 1-2 is strictly supermodular are:

$H_{0}: h_{0}<0$ and $h_{1}<0$ and $h_{2}<0$ and $h_{3}<0$ (null hypothesis)

$H_{1}: h_{0} \geq 0$ or $h_{1} \geq 0$ or $h_{2} \geq 0$ and $h_{3} \geq 0 \quad$ (alternative hypothesis)

where $h_{s}=-\gamma_{0+s}+\gamma_{4+s}+\gamma_{8+s}-\gamma_{12+s}, s=0,1,2,3$. The test is based on Kodde and Palm's (1986) Wald test for inequalities. The tests for other pairs were defined analogously. Similarly, testing the strict submodularity for the pair 1-2 concerned the following hypotheses: HO: $h 0>0$ and $h 1>0$ and $h 2>0$ and $h 3>0, H 1: h 0 \leq 0$ or $h 1 \leq 0$ or $h 2 \leq 0$ and $h 3 \leq 0$.

\footnotetext{
${ }^{2}$ Note that practices 1 to 4 denote business practices, knowledge management, workplace organization and external relations.
} 
We also performed the same tests of complementarity and substitutability for innovation performance based on consistent estimates of equation (2). These tests were defined very analogously replacing $\gamma_{j}$ with $\delta_{j}$. When estimating equation (2), variable s0_1_0_1 was excluded from our regressions because of collinearity. The tests therefore included the additional constraint $\delta_{5}=0 .{ }^{3}$

\section{Data and variables}

The empirical analysis is based on firm-level data drawn from the Luxembourgish Community Innovation Survey (CIS2006) carried out in Luxembourg in 2008 by CEPS/INSTEAD on behalf and under the methodological responsibility of the National Statistical Institute (STATEC). The objective of this survey was to collect data on firms' innovation behavior over the three-year period from 2004 to 2006, according to the OECD (2005) recommendations. It provides a set of general information concerning the firms (sector of activity, group belonging, number of employees, sales, geographic market), information about technological and non-technological innovation as well as perceptions of factors hampering innovation activities or subjective evaluation of the effects of innovation. The dataset also comprises information about sources of information and various types of R\&D cooperation for innovation activities. For the purpose of this paper, we used a sub-sample of firms with at least 10 employees that operated in the manufacturing and the service sectors. With the dataset including manufacturing and service firms, the paper adopts the synthesis approach, which allows for innovation to take place in manufacturing and in services (Gallouj and Weinstein, 1997; Love and Mansury, 2007). ${ }^{4}$ We thus obtained a sample of 568 representative firms.

Three dependent variables are used. The first is innovation performance, measured as the percentage of total turnover from product innovations that are new to the firm (Mohnen and Röller, 2005; Cassiman and Veugelers, 2006). The second dependent variable is the propensity of innovation in product, a binary variable that indicates whether the firm had introduced product innovation or not. The third dependent variable, propensity of innovation

\footnotetext{
${ }^{3}$ It should be noted that tests can be also performed on the selection equation for product innovation while using the Heckman's selection model for estimating (2). We prefer not to present them here as they are consistent with those based on equation (1) applied to product innovation.

${ }^{4}$ Moreover, doing so would result in missing observations, which could seriously affect the quality of the regressions.
} 
in process, is binary and indicated whether or not a firm was a process innovator (cf. Appendix A for the definition of variables).

The CIS provides data on organizational innovation implemented by firms during the 2004-2006 period. Four practices of organizational innovation are categorized in the survey: (1) new business practices for organizing work and procedures (i.e. supply chain management, business reengineering, quality management, lean production, and education/training systems), (2) new knowledge management systems (i.e. new systems facilitating exchange of information, knowledge and skills within the firm or designed to collect and interpret information), (3) new workplace organization methods (i.e. new systems of employee responsibilities, team work, decentralization, integration or de-integration of departments, etc.) and (4) new methods of organizing external relations (i.e. first use of alliances, partnerships, outsourcing or sub-contracting, etc). Four binary variables were constructed for each of these practices. ${ }^{5}$

We also included other classical technological innovation determinants in our model. $R \& D$ intensity was measured as the sum of expenditures on intramural (in-house) $R \& D$ and extramural R\&D in 2006 divided by the total turnover in 2006. Firms were asked to rate the degree of competition of the market on a Likert scale from 0 (no effective competition) to 3 (very intensive). On the basis of this information, we constructed a competition intensity variable. Two binary variables on appropriability conditions were also included. Strategic protection is equal to 1 if the score for the importance of strategic protection methods "secrecy", "complexity of design" or "lead-time advantage over competitors" is "crucial" and 0 otherwise. Formal protection is equal to 1 if the score for the importance of formal protection methods "patents", "trademarks", "registration of design patterns" or "copyrights" is "crucial" and 0 otherwise.

A number of traditional control variables were also included in our model. Firm size is measured by the natural logarithm of the number of employees. We also introduced a dummy variable group belonging, taking the value 1 if the firm was independent (reference), 2 if the firm belonged to a domestic group, 3 if it was part of a European group and 4 if it was part of an extra-European group. Eight sectors of activities were included, according to the two-digit NACE classification: (1) high and medium high-tech manufacturing industry; (2) medium

\footnotetext{
${ }^{5}$ Indeed, modeling complementarities in terms of supermodular functions on lattices highlights the fact that "design choices, if they can even be adapted at will, represent discrete rather than continuous variables" (Ennen and Richter, 2010: 214).
} 
low-tech industry; (3) low-tech industry; (4) transport and communication; (5) financial intermediation; (6) computer activities; (7) R\&D - engineering activities and consultancy, technical testing and analysis and (8) wholesale trade (reference).

\section{Results and discussion}

Our dataset contained 568 observations and can be considered as being of moderate size. However, in order to keep our results robust, we computed the bootstrap standard errors for estimated coefficients, which make it possible to avoid a possible finite sample size bias.

As the dependent variables in Equations 1 and 2 are respectively the percentage of sales attributable to innovative products and the probability of being a product innovator, consistent estimates for the parameters of interest can be obtained by maximum likelihood estimation, which accounts for censoring in innovation performance (Mohnen and Röller, 2005). The inverse Mill's ratio included in the model for correcting left-censoring is, however, not significant. This indicates that the estimated results for sales of innovative products are not influenced by censoring. Therefore, a simple Tobit model was used in order to estimate innovation performance. Results are reported in Table 1.

\section{- INSERT TABLE 1 ABOUT HERE -}

In order to analyze the complementary relationship of the four organizational practices, we also assessed the impact of organizational practices on the probability of the firm to be product and process innovators using a biprobit model. The results are presented in Table 2.

\section{- INSERT TABLE 2 ABOUT HERE -}

Results in Table 1 and 2 show that the probability of being product or process innovators strongly depends on $R \& D$ intensity, which is in line with previous empirical findings indicating the crucial role of internal $R \& D$ expenditures in innovation processes as they condition knowledge creation as well as the firms' capacity to absorb external knowledge (Crépon et al., 1998). On the contrary, R\&D intensity did not have any impact on the innovation performance measured as a percentage of new products in sales. Firm size was found to be positively correlated to the likelihood of product innovation, but negatively to the extent of innovation. This result that the larger the size of the firm, the greater the propensity to innovate in products but the smaller the innovative performance, is in line with previous empirical findings (Mohnen and Röller, 2005). Strategic protection methods are strongly and 
positively associated with the likelihood of product or process innovation while having no impact on product innovation performance. As expected, firms making intensive use of formal innovation protections such as patents, trademarks or registration of design patterns have a higher probability to innovate in terms of goods and services.

Turning to organizational innovation practices, results show that, when adopted separately, workplace organization and knowledge management have a significant positive impact on product innovation performance, whereas business practices have a significant positive impact on the propensity to innovate in products. The simultaneous implementation of business practices, knowledge management and workplace organization increases the propensity to innovate in process and in product, whereas no effects of such combinations were observed on innovation performance. However, some similarities between practices were found. For example, firms that implemented all four organizational practices jointly were significantly more likely to be process innovators and to show higher innovation performance.

Although these results give some indications of the effects of different combinations of organizational practices on innovation output, it is however important to recall that the individual significance and signs of the coefficients do not by themselves provide information as to the complementarity or substitutability between different organizational practices. Testing for complementarity involves testing linear inequality restrictions and the joint distribution of several of these restrictions (Mohnen and Röller, 2005; Love and Roper, 2009). In our case, assessing complementarity or substitutability between organizational practices required the joint testing of four inequality constraints for each pair-wise comparison. The results of supermodularity and submodularity tests are provided in Tables 3 and 4.

\section{- INSERT TABLE 3 ABOUT HERE - \\ - INSERT TABLE 4 ABOUT HERE -}

Similarly to Mohnen and Röller (2005), we reported the values provided by Kodde and Palm (1986) for the lower and the upper bounds of the tests at the $10 \%$ significance level. The numbers of degrees of freedom are computed as 1 plus the number of equality restrictions $(q+1)$ for the lower bound, and as the total number of equality and inequality $(p)$ for the upper bound. For the model in equation (1), i.e. product and process innovations, the lower and upper bounds at the $10 \%$ level are 1.642 (degrees of freedom = 1) and $7.094(d f=4)$, respectively. The null hypothesis $H_{0}$ is rejected if the test statistic is higher than the upper bound. $H_{0}$ is accepted if the test statistic is lower than the lower bound. The test is inconclusive for values in between the two bounds. For equation (2), i.e. product innovation 
performance, the lower and upper bounds at the $10 \%$ level are $3.808(\mathrm{df}=2)$ and $8.574(\mathrm{df}=$ 5), respectively 6 .

Results in Table 3 and 4 show that the pattern of complementarity between organizational practices may depend on the type of innovation, i.e. product or process. Indeed, as regards the propensity to innovate equation, there is significant evidence of complementarity between knowledge management and business practices (pair 1-2) on process innovation, whereas results for product innovation are inconclusive. Firms combining these two practices tended to benefit more from flexibility, adaptability and knowledge increase, which may in turn lead to a higher capacity to introduce process innovation - new methods of producing goods or services, new operations for purchasing, accounting or computing. Results also underline the complementary effect of knowledge management and work organization (pair 2-3) on product innovation.

Results for the propensity to innovate in products also show some similarities with those for the propensity to innovate in process. First, the joint implementation of knowledge management and external relations (pair 2-4) decreases the propensity to innovate in both product and process, thus representing the substitution effect of pair 2-4. This finding suggests that these organizational practices are jointly substitutable in determining whether a firm is innovative or not. In other words, the implementation of one of the two practices in each pair should be sufficient to motivate a firm to innovate. Second, there is clear evidence of substitution, both for product and process innovations, between business practices and workplace organization (pair 1-3). The benefits of practices such as low level of hierarchy, high level of delegation and broad skills, team working or job rotation are reduced when firms implement them jointly with workplace organization (lean production, supply chain management, business reengineering or quality management). This finding may be accounted for by the high costs that firms have to support as the result of the simultaneous implementation of such practices, which impedes rather than stimulates firm innovation capacities.

Results also show that the patterns of complementarity may also differ according to whether the firm is in the first step of the innovation process (i.e. being product innovator or not) or in a subsequent step (i.e. the product innovative performance). A complementary relationship between business practices and knowledge management (pair 1-2) was found for

\footnotetext{
${ }^{6}$ For product and process innovations (equation 1), the number of degrees of freedom for the lower bound is equal to 1 because there is no equality restriction whereas, for product innovative performance (equation 2), it is equal to 2 because there is, as shown earlier, an equality restriction $\delta_{5}=0$.
} 
product innovative performance whereas the test is inconclusive for the probability to be product innovator. The benefits from the positive synergies between business practices and knowledge management are limited to the latter stage of the innovation process. Innovative products are thus successfully adopted by the market, leading firms to achieve higher performance from these new products when they are able to combine organizational practices such as supply chain management, quality management or business reengineering with knowledge management. The pattern of complementarity is the same for the relationship between business practices and external relations (pair 1-4) and between workplace organization and external relations (pair 3-4): complementarity is observed in the latter stage of innovation process (i.e. innovative performance) whereas the test results are inconclusive for the first stage (i.e. product innovation).

On the contrary, the relationship between business practices and workplace organization (pair 1-3) was found to be complementary at the second stage of the innovation process but substitutable at the first stage. This result, as expected from the competence-based theory viewpoint, highlights the evidence that in modern business environments (Milgrom and Roberts, 1995), strategic cost and quality management, considered as critical factors for firms' commercial success, need to be jointly implemented within a high performance work organization which, simultaneously, facilitates knowledge integration, information exchange and mutual learning. Firms that jointly implement knowledge management and workplace organization (pair 2-3) are more likely to have a higher probability of introducing product innovation whereas this combination seems to reduce product innovation performance, results that are in line with Laursen and Mahnke (2001). This suggests that synergies from team work, employees' responsibilities, decentralization and internal knowledge management are likely to be more fruitful in a more upstream technical and engineering stage (conception and introduction of new or significantly improved goods or services) than in a downstream product stage (launching and commercializing these goods or services on the market).

\section{Conclusion}

The objective of this paper was to understand whether different organizational innovation practices are complements or substitutes for technological innovation performance. We used the supermodulartiy theory à la Milgrom and Roberts, which theorem makes it possible to create supermodular functions in order to demonstrate the effect of complementarity between organizational strategies in technological innovation. The empirical study was based on the firm-level dataset drawn from the Luxembourgish Community Innovation Survey (CIS 2006). 
To our knowledge, this study is the first to assess the firm's organizational innovation management from an integrative and holistic viewpoint by analyzing the pattern of complementarity of different organizational practices through their impact on firms' innovation, taking into account the two stages of innovation processes.

Overall, our results highlight some important evidence on the relationship between organizational practices. First, we show the crucial role of organizational innovation by providing empirical evidence in favour of the impact of complementary organizational practices management on raising firms' innovation, supporting previous theoretical studies (Teece; 1986; Stieglitz and Heine, 2007).

Second, the patterns of complementarity between organizational practices differ according to the type of innovation (product or process) under consideration - although some similarities were highlighted. One example is the joint implementation of knowledge management and workplace organization which is substitutable in terms of probability to innovate in products whereas it complements in terms of the probability to be a process innovator. This indicates that the two types of innovation are subject to different organizational management tools.

Third, the pattern of complementarity between organizational practices also differs according to whether the firm is in the first stage of the innovation process or in a later stage. Whereas complementarity among organizational practices seems more frequent for product innovation performance, results for the propensity to innovate in products show a number of substitutable relationships - or inconclusive evidence. Business practices, for instance, when implemented simultaneously with knowledge management, workplace organization or external relations, paid off more than its isolated adoption in terms of product innovation performance. On the contrary, we found rather a substitutable relationship between business practices and workplace organization for the propensity to innovate. This can logically be explained by the fact that business practices per se do not help firms to become innovators (other determinants being much more important). However, such practices are key when it comes to the success of innovative products: for instance, supply chain management ensures a management-efficient relationship with suppliers and customers, quality management brings value to consumers by enhancing the quality of products, lean management may contribute to lowering product costs, etc.

These results highlight the complexity of managing organizational practices with regards to increasing firms' innovation, they also highlight the combinations of organizational innovation practices that reinforce technological innovation performance. Some practices 
should be adopted simultaneously in order to achieve an optimal effect, whereas others are productive on their own - and others yet are counterproductive for innovation. Managers should therefore be aware of the various effects of these organizational innovation practices for technological innovation. Studying such relationships among individual elements or factors, in particular organizational innovation practices, therefore offers valuable insight (Ennen and Richter, 2010). The present study helps firms that sometimes have limited resources to choose the appropriate organizational innovation practice for subsequent technological innovation.

Our paper is not exempt from certain limitations and the empirical evidence of this paper should be considered preliminary for several reasons. First, the theoretical framework for complementarities in organizational innovation is under construction, given that research has essentially focused on technological innovation on one hand and on work and human resource practices, as far as complementarities are concerned, on the other hand.

Second, although the focus on a single country is an obvious limitation, comparison between countries is difficult as the various national CIS have retained different definitions for organizational innovation practices. Moreover, as argued by Armbruster et al. (2008), it would be interesting to compare our results with other large-scale surveys (e.g. NUTEK, DRUID, EPOC, INNFORM, COI) that use different measures both for organizational innovations and for technological innovation in order to generalize our results to other types of organizational practices. This could partly solve the issue of partial overlapping between some of the sub-organizational dimensions contained in the CIS categories ${ }^{7}$.

Third, and subsequent to the aforementioned limitation of single-country studies, results may be influenced by the specific economic structure of Luxembourg, where service firms are mostly large and established companies such as those in banking, whereas the manufacturing sector is composed mainly of SMEs. Our results, however, do not emphasize significant differences between the manufacturing and the service industries, providing support for the adoption of a "synthesis" approach to the study of innovation, an integrative view that allows for innovation to take place in manufacturing and in services (Gallouj and Weinstein, 1997; Love and Mansury, 2007).

Fourth, our results are static in nature and are only tentative, as the causal direction cannot be asserted in the absence of longitudinal dynamic studies. Indeed, it is now largely

\footnotetext{
${ }^{7}$ We preferred to work with the CIS 2006 - and not with the most recent CIS 2008, as the latter agglomerates knowledge management and business practices, which does not solve potential overlaps and slightly impoverishes the analysis.
} 
recognized that it is problematic to address the endogeneity issue and make statements about directions of causality using cross-sectional data that do not make it possible to determine whether the same firms are innovative every year or what keeps firms innovative over time. Future research could address this gap by using a dynamic panel data model to analyze the complementarities between technological and organizational, or more generally speaking nontechnological (including marketing) innovations. This was not possible here as the definition and categories for organizational innovation have changed with each CIS survey (for instance, three categories in the CIS6, four in the CIS4).

Finally, this study has focused on organizational strategies and on their complementary effect on technological innovation. Our mixed results are therefore partly due to the limited number of organizational practices taken into account. Future studies could take into account a larger set of non-technological innovation practices, such as marketing, management or strategic innovations, but also resources, strategies, and external factors (e.g. demand conditions, institutional environment, cf. Ennen and Richter, 2010) to better fit with the original idea of the supermodular modern manufacturing firm (Milgrom and Roberts, 1990). This type of study on multiple elements should yield more complementarity effects, as these are largely a systems-specific phenomenon (Ennen and Richter, 2010). This present analysis represents a small step along the path to achieving greater knowledge concerning the variety of innovation patterns and complementarities, especially between organizational and technological innovations. Much work remains ahead to fully understand the complementary effects of different types of innovation.

\section{References}

Armbruster, H., Bikfalvib, A., Kinkela, S., Lay, G. 2008. Organizational innovation: The challenge of measuring non-technical innovation in large-scale surveys. Technovation 28: 644-657.

Arora, A., Gambardella, A. 1990. Complementarity and external linkages: The strategies of the large firms in biotechnology. Journal of Industrial Economics 38(4): 362-379.

Athey, S., Stern, S. 1998. An empirical framework for testing theories about complementarity in organizational design. NBER Working Paper.

Audretsch, D.B., Menkveld, A.J., Thurik, A.R. 1996. The decision between internal and external R\&D. Journal of Institutional and Theoretical Economics 152: 517-530. 
Bocquet, R., Brossard, O., Sabatier, M. 2007. Complementarities in organizational design and the diffusion of information technologies: An empirical analysis. Research Policy 36(3): 367-386.

Cappelli, P., Newmark, D. 2001. Do high-performance work practices improve establishmentlevel outcomes? Industrial \& Labor Relations Review 54: 737-775.

Carree, M., Lokshin, B., Belderbos, R. 2011. A note on testing for complementarity and substitutability in the case of multiple practices. Journal of Productivity Analysis 35(3): 263-269.

Cassiman, B., Veugelers, R. 2006. In search of complementarity in innovation strategy: Internal $\mathrm{R} \& \mathrm{D}$, cooperation in $\mathrm{R} \& \mathrm{D}$ and external technology acquisition. Management Science 52(1): 68-82.

Catozzella, A., Vivarelli, M. 2007. Beyond the knowledge production function: The role of R\&D in a multi-faceted innovation process. Jena Economic Research Papers in Economics, 007-087.

Cozzarin, B.P., Percival, J.C. 2006. Complementarities between organisational strategies and innovation. Economics of Innovation and New Technology 15(3): 195-217.

Crépon, B., Duguet, M., Mairesse, J. 1998. Research and development, innovation and productivity: An econometric analysis at the firm level. Economics of Innovation and New Technology 7(2): 115-158.

Ennen, E., Richter, A. 2010. The Whole Is More Than The Sum of Its Parts - Or Is It? A Review of the Empirical Literature on Complementarities in Organizations. Journal of Management 36(1): 207-233.

Evangelista, R., Vezzani, A. 2010. The economic impact of technological and organizational innovations. A firm-level analysis. Research Policy 39, 1253-1263.

Galia, F., Legros, D. 2004. Complementarities between obstacles to innovation: Evidence from France. Research Policy 33: 1185-1199.

Gallouj, F., Weinstein, O. 1997. Innovation in services. Research Policy 26, 537-556.

Günday, G., Ulusoy, G., Kılıç, K., Alpkan, L. 2011. Effects of innovation types on firm performance. International Journal of Production Economics 133(2): 662-676.

Ichniowski, C., Shaw, K., Prennushi, G. 1997. The effects of human resource management practices on productivity: A study of steel finishing lines. American Economic Review 87(3): 291-313.

Kodde, D.A., Palm, F.C. 1986. Wald criteria for jointly testing equality and inequality restrictions. Econometrica 54: 1243-1248. 
Laursen, K., Mahnke, V. 2001. Knowledge Strategies, Firm Types, and Complementarity in Human-Resource Practices. Journal of Management and Governance 5(1): 1-27.

Lokshin, B., Belderbos, R., Carree, M. 2008a. The productivity effects of internal and external R\&D. Evidence from a dynamic panel data model. Oxford Bulletin of Economics and Statistics 70(3): 399-413.

Love, J.H., Mansury M.A. 2007. External linkages, R\&D and innovation performance in US business services. Industry and Innovation 14(5): 477-496.

Love, J.H., Roper, S. 2001. Location and network effects on innovation success: Evidence for UK, German and Irish manufacturing plants. Research Policy 30(4): 643-661.

Love, J.H., Roper, S. 2009. Organizing innovation: Complementarities between crossfunctional teams. Technovation 29: 192-203.

Milgrom, P., Roberts, J. 1990. The economics of modern manufacturing: Technology, strategy and organization. American Economic Review 80(3): 511-28.

Milgrom, P., Roberts, J. 1995. Complementarities and fit: Strategy, structure and organizational change in manufacturing. Journal of Accounting and Economics 19: 179208.

Miravete, E.J., Pernias, J.C. 2006. Innovation complementarity and scale of production. The Journal of Industrial Economics LIV: 1-29.

Mohnen, P., Röller, L. 2005. Complementarities in innovation policy. European Economic Review 49: 1431-1450.

OECD 2005. Oslo Manual, $3^{\text {rd }}$ edition. OECD/Eurostat: OECD Publishing.

Schmiedeberg, C. 2008. Complementarities of innovation activities: An empirical analysis of the German manufacturing sector. Research Policy 37: 1492-1503.

Stieglitz, N., Heine, K. 2007. Innovations and the role of complementarities in a strategic theory of the firm. Strategic Management Journal 28: 1-15.

Teece, D.J. 1986. Profiting from technological innovation. Research Policy 15: 285-305.

Topkis, D.M. 1998. Supermodularity and Complementarity. Princeton, NJ. 


\begin{tabular}{|c|c|}
\hline Variable & $\begin{array}{c}\text { Coefficient } \\
\text { (std.err.) }\end{array}$ \\
\hline Intensity of R\&D & $0.003(0.004)$ \\
\hline Intensity of competition & $-0.001(0.012)$ \\
\hline Formal protection & $-0.011(0.018)$ \\
\hline Strategic protection & $0.011(0.018)$ \\
\hline Size & $-0.011(0.006) *$ \\
\hline Belonging to Luxembourgish group & $-0.005(0.021)$ \\
\hline Belonging to European group & $-0.005(0.024)$ \\
\hline Belonging to other countries group & $0.016(0.031)$ \\
\hline High and medium high technology industry & $0.012(0.030)$ \\
\hline Medium technology industry & $0.038(0.033)$ \\
\hline Low technology industry & $0.014(0.026)$ \\
\hline Transport and communication & $0.028(0.032)$ \\
\hline Financial intermediations & $0.046(0.021) * *$ \\
\hline Computer activities & $0.026(0.033)$ \\
\hline R\&D - engineering activities and consultancy & $-0.004(0.024)$ \\
\hline s0_0_0_1 & $0.003(0.036)$ \\
\hline SO_O_1_O & $0.121(0.055) * *$ \\
\hline s0_0_1_1 & $0.031(0.033)$ \\
\hline SO_1_O_O & $0.100(0.040) * *$ \\
\hline s0_1_1_0 & $-0.017(0.039)$ \\
\hline sO_1_1_l & $-0.079(0.031) * * *$ \\
\hline s1_0_0_0 & $0.014(0.024)$ \\
\hline S1_O_O_l & $0.023(0.035)$ \\
\hline S1_O_I_O & $0.052(0.044)$ \\
\hline s1_O_l_l & $0.016(0.038)$ \\
\hline S1_1_O_O & $0.036(0.037)$ \\
\hline$s 1 \_1 \_0 \_1$ & $0.004(0.040)$ \\
\hline$s 1 \_1 \_1 \_0$ & $0.021(0.027)$ \\
\hline$s 1 \_1 \_1 \_1$ & $0.058(0.027) * *$ \\
\hline Intercept & $0.058(0.083)$ \\
\hline Observation & 266 \\
\hline Mill's ratio & $0.048(0.048)$ \\
\hline
\end{tabular}


Notes. The dependent variable is innovative performance, measured as the share of sales of innovative products. Estimation results obtained from the Heckman two-step selection model (the first step corresponds to the selection equation for product innovation, the second step corresponds to the performance equation for product innovation). Dummy variables $s k \_l \_m \_n$ (where $\left.k, l, m, n=0,1\right)$ correspond to the possible

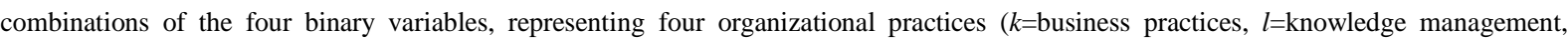
$m=$ workplace organization, $n=$ external relations). Variable s0_1_0_1 was excluded from the regression because of collinearity. Number of observations: 568 . Number of uncensored observations: 266 . *, ** and $* * *$ denote significance at the levels of $10 \%, 5 \%$ and $1 \%$, based on bootstrap standard errors with 100 replications.

Table 2: Estimation results for product and process innovations

\begin{tabular}{|c|c|c|}
\hline & Product innovation & Process innovation \\
\hline Variable & $\begin{array}{c}\text { Coefficient } \\
\text { (std.err.) }\end{array}$ & $\begin{array}{c}\text { Coefficient } \\
\text { (std.err.) }\end{array}$ \\
\hline Intensity of $\mathrm{R} \& \mathrm{D}$ & $0.204(0.028)^{* * *}$ & $0.110(0.019)^{* * *}$ \\
\hline Intensity of competition & $-0.010(0.096)$ & $0.157(0.096)$ \\
\hline Formal protection & $0.465(0.205)^{* *}$ & $-0.086(0.209)$ \\
\hline Strategic protection & $0.408(0.168)^{* *}$ & $0.370(0.168)^{* *}$ \\
\hline Size & $0.123(0.071)^{*}$ & $0.036(0.069)$ \\
\hline Belonging to Luxembourgish group & $0.200(0.205)$ & $-0.074(0.180)$ \\
\hline Belonging to European group & $0.216(0.192)$ & $0.210(0.187)$ \\
\hline Belonging to other countries group & $0.689(0.368)^{*}$ & $0.162(0.260)$ \\
\hline High and medium high technology industry & $0.105(0.301)$ & $0.462(0.273)^{*}$ \\
\hline Medium technology industry & $-0.323(0.255)$ & $0.367(0.280)$ \\
\hline Low technology industry & $-0.637(0.245)^{* * *}$ & $0.369(0.256)$ \\
\hline Transport and communication & $-0.662(0.271)^{* *}$ & $0.215(0.261)$ \\
\hline Financial intermediations & $-0.006(0.253)$ & $0.533(0.299)^{*}$ \\
\hline Computer activities & $-0.370(0.375)$ & $-0.000(0.337)$ \\
\hline $\mathrm{R} \& \mathrm{D}-$ engineering activities and consultancy & $-0.177(0.281)$ & $-0.197(0.307)$ \\
\hline sO_O_O_1 & $1.347(2.003)$ & $-0.318(2.733)$ \\
\hline sO_O_1_O & $0.158(0.344)$ & $0.007(0.415)$ \\
\hline s0_0_1_1 & $0.297(0.435)$ & $0.614(0.373)^{*}$ \\
\hline sO_1_O_O & $0.900(1.385)$ & $-0.075(2.546)$ \\
\hline sO_1_O_1 & $-5.017(0.701) * * *$ & $-5.124(0.582)^{* * *}$ \\
\hline sO_1_1_0 & $1.371(1.379)$ & $0.462(0.458)$ \\
\hline sO_1_1_l & $-0.586(2.434)$ & $-5.945(0.654)^{* * *}$ \\
\hline S1_O_O_O & $0.512(0.308)^{*}$ & $0.308(0.270)$ \\
\hline S1_0_0_1 & $-0.533(2.427)$ & $0.028(2.106)$ \\
\hline$s 1 \_0 \_1 \_0$ & $0.295(0.320)$ & $0.813(0.254)^{* * *}$ \\
\hline s1_0_1_1 & $1.057(1.555)$ & $1.193(0.422)^{* * *}$ \\
\hline
\end{tabular}




\begin{tabular}{|c|c|c|}
\hline S1_1_O_O & $0.586(0.394)$ & $0.890(0.343)^{* * *}$ \\
\hline s1_1_0_1 & $1.346(2.323)$ & $0.155(1.816)$ \\
\hline s1_1_1_0 & $0.599(0.243)^{* *}$ & $0.688(0.238)^{* * *}$ \\
\hline s1_1_l_l & $0.237(0.249)$ & $0.662(0.199) * * *$ \\
\hline Intercept & $-1.471(0.437) * * *$ & $-2.292(0.422) * * *$ \\
\hline Observation & \multicolumn{2}{|c|}{568} \\
\hline $\operatorname{atanh} \rho$ & \multicolumn{2}{|c|}{$0.540(0.113)^{* * *}$} \\
\hline $\operatorname{LR} \chi^{2}(1)$ & \multicolumn{2}{|c|}{$31.267 * * *$} \\
\hline
\end{tabular}

Notes. The dependent variables correspond to the probabilities of product innovation and process innovation. Estimation results are obtained from a biprobit regression. Dummy variables $s k \_l \_m \_n$ (where $\left.k, l, m, n=0,1\right)$ correspond to the possible combinations of the four binary variables, representing four organizational practices ( $k=$ business practices, $l=$ knowledge management, $m=$ workplace organization, $n=$ external relations). Number of observations: 568. atanh $\rho=0.5 \ln [(1+\rho) /(1-\rho)]$ corresponds to the covariance between the two error terms of equation (1) for product innovation and process innovation. The likelihood ratio (LR) $\chi^{2}(1)$ test is for $\rho=0$. *, ** and *** denote significance at the levels of $10 \%, 5 \%$ and $1 \%$, based on bootstrap standard errors with 100 replications.

Table 3: Supermodularity and submodularity for product innovation performance

\begin{tabular}{lrrrrrr}
\hline \hline Wald test & pair 1-2 & pair 1-3 & pair 1-4 & pair 2-3 & pair 2-4 & pair 3-4 \\
\hline Supermodularity & $0.121 \mathrm{~A}$ & $0.441 \mathrm{~A}$ & $0 \mathrm{~A}$ & $9.565 \mathrm{R}$ & $0.759 \mathrm{~A}$ & $0.499 \mathrm{~A}$ \\
Submodularity & $11.982 \mathrm{R}$ & $11.016 \mathrm{~N}$ & $11.173 \mathrm{R}$ & $0.665 \mathrm{~A}$ & $1.428 \mathrm{~A}$ & $3.938 \mathrm{~N}$ \\
\hline \hline
\end{tabular}

Notes. Tests are based on consistent estimates for the equation of product innovative performance (Heckman's model). The lower and the upper bounds of the test are respectively $3.808(\mathrm{df}=2)$ and $8.574(\mathrm{df}=5)$. A the null hypothesis $H_{0}$ is accepted (if the test statistic is lower than the lower bound), ${ }^{\mathrm{R}} H_{0}$ is rejected (if the test statistic is higher than the upper bound), ${ }^{\mathrm{N}}$ no conclusion (otherwise).

Table 4: Supermodularity and submodularity for product and process innovation

\begin{tabular}{llrrrrrr}
\hline \hline & Wald test & pair 1-2 & pair 1-3 & pair 1-4 & pair 2-3 & pair 2-4 & pair 3-4 \\
\hline Product & Supermodularity & $2.896 \mathrm{~N}$ & $9.003 \mathrm{R}$ & $2.210 \mathrm{~N}$ & $0.914 \mathrm{~A}$ & $17.149 \mathrm{R}$ & $1.875 \mathrm{~N}$ \\
& Submodularity & $5.845 \mathrm{~N}$ & $0.793 \mathrm{~A}$ & $6.362 \mathrm{~N}$ & $3.333 \mathrm{~N}$ & $0.374 \mathrm{~A}$ & $1.720 \mathrm{~N}$ \\
\hline Process & Supermodularity & $1.278 \mathrm{~A}$ & $7.193 \mathrm{R}$ & $0.495 \mathrm{~A}$ & $1.833 \mathrm{~N}$ & $49.453 \mathrm{R}$ & $0.604 \mathrm{~A}$ \\
& Submodularity & $52.739 \mathrm{R}$ & $0.539 \mathrm{~A}$ & $59.184 \mathrm{R}$ & $0 \mathrm{~A}$ & $0 \mathrm{~A}$ & $0.241 \mathrm{~A}$ \\
\hline \hline
\end{tabular}

Notes. Tests are based on consistent estimates of product and process innovations (biprobit regression). The lower and the upper bounds of the test at the $10 \%$ level (see Kodde and Palm, 1986) are respectively 1.642 (degrees of freedom $=1)$ and $7.094(\mathrm{df}=4)$. A the null hypothesis $H_{0}$ is accepted (if the test statistic is lower than the lower bound), ${ }^{\mathrm{R}} H_{0}$ is rejected (if the test statistic is higher than the upper bound), ${ }^{\mathrm{N}}$ no conclusion (otherwise).

\section{Appendix A. Definition of variables}




\begin{tabular}{|c|c|}
\hline Variables & Description \\
\hline $\begin{array}{l}\text { Innovation } \\
\text { performance } \\
\text { Propensity to } \\
\text { innovate in product } \\
\text { Propensity to } \\
\text { innovate in process }\end{array}$ & $\begin{array}{l}\text { Percentage of total turnover in } 2006 \text { from goods and service innovations introduced } \\
\text { during } 2004 \text { to } 2006 \text { that are new to the firm } \\
\text { Equal } 1 \text { if the firm introduced new or significantly improved goods or/and services } \\
\text { during the three years } 2004 \text { to } 2006,0 \text { otherwise } \\
\text { Equal } 1 \text { if the firm introduced new or significantly improved production process, } \\
\text { distribution methods, or support activity for goods or services during the three years } \\
2004 \text { to } 2006,0 \text { otherwise }\end{array}$ \\
\hline \multicolumn{2}{|c|}{ Organizational innovation practices } \\
\hline Business practices & $\begin{array}{l}\text { Equal } 1 \text { if the firm introduced new business practices for organizing work or } \\
\text { procedures (i.e. supply chain, business re-engineering, lean production, quality } \\
\text { management), } 0 \text { otherwise }\end{array}$ \\
\hline $\begin{array}{l}\text { Knowledge } \\
\text { management }\end{array}$ & $\begin{array}{l}\text { Equal } 1 \text { if the firm introduced new knowledge management systems to use or exchange } \\
\text { better information, knowledge, skills within the firm or to collect and interpret } \\
\text { information from outside the firm, } 0 \text { otherwise }\end{array}$ \\
\hline $\begin{array}{l}\text { Workplace } \\
\text { organization }\end{array}$ & $\begin{array}{l}\text { Equal } 1 \text { if the firm introduced new methods of workplace organization for distributing } \\
\text { responsibilities and decision making (team work, decentralization, integration or de- } \\
\text { integration of departments), } 0 \text { otherwise }\end{array}$ \\
\hline $\begin{array}{l}\text { External relations } \\
\text { Innovation activitie }\end{array}$ & $\begin{array}{l}\text { Equal } 1 \text { if the firm introduced new methods of organizing external relations with other } \\
\text { firms or public institutions (partnerships, outsourcing, sub-contracting), } 0 \text { otherwise }\end{array}$ \\
\hline $\begin{array}{l}\text { R\&D intensity } \\
\text { Competition contex }\end{array}$ & $\begin{array}{l}\text { Sum of expenditures for intramural (in-house) R\&D and extramural R\&D in } 2006 \\
\text { divided by the total turnover in } 2006\end{array}$ \\
\hline $\begin{array}{l}\text { Competition } \\
\text { intensity } \\
\text { Appropriability }\end{array}$ & $\begin{array}{l}\text { Rate the degree of competition of the market on a Likert scale from } 0 \text { (no effective } \\
\text { competition) to } 3 \text { (very intensive) }\end{array}$ \\
\hline Formal protection & $\begin{array}{l}\text { Equal to } 1 \text { if the score for the importance of formal protection methods "patents", } \\
\text { "trademarks", "registration of design patterns" or "copyrights" is "crucial" and } 0 \\
\text { otherwise }\end{array}$ \\
\hline Strategic protection & $\begin{array}{l}\text { Equal to } 1 \text { if the score for the importance of strategic protection methods "secrecy", } \\
\text { "complexity of design" or "lead-time advantage over competitors" is "crucial" and } 0 \\
\text { otherwise }\end{array}$ \\
\hline Size, group, sector & \\
\hline Size & Logarithm of the number of employees \\
\hline Group belonging & $\begin{array}{l}\text { Equal to } 1 \text { if not part of a group (reference); equal to } 2 \text { if part of a national enterprise } \\
\text { group; equal to } 3 \text { if part of a European enterprise group; equal to } 4 \text { if part of an extra- } \\
\text { European enterprise group }\end{array}$ \\
\hline
\end{tabular}


High and medium high-tech manufacturing industry; medium low-tech manufacturing industry; low-tech manufacturing industry; transport and communication; financial intermediation; computer activities; R\&D - engineering activities and consultancy, technical testing and analysis and wholesale trade (reference) 


\section{Appendix B: Analysis of correlation between organizational practices ('adoption' approach)}

The intuition is based on the idea that complementarities create a force in favour of positive correlation between two activities. If alternative activities are complementary, then we would expect rationally behaving firms to exploit this opportunity, investing in these activities at the same time and in the same direction. However, Athey and Stern (1998) noted that two activities could be correlated without being complements and/or that the potential correlation may be hidden by the influence of a common set of exogenous factors. In order to address this problem, conditional correlations were calculated based on the residuals of reduced-form regressions of the activities on a common set of exogenous variables. The presence of positive (negative) conditional correlation coefficients may imply complementarity (substitutability) between two activities.

This approach has been by far the most simple and popular among empirical researchers for testing complementarity (Arora and Gambardella, 1990; Ichniowski et al., 1997; Galia and Legros, 2004; Bocquet et al., 2007). The advantage of this approach is that it provides supportive evidence of complementarity if activities are adopted simultaneously, without requiring any performance measure. Despite this advantage and its relatively simple implementation, it does not provide a sufficient condition to conclude that a possible complementarity relationship exists between activities. It is complementarity that implies, under some conditions, positive correlation - but the reverse is not always true (Catozzella and Vivarelli, 2007).

We evaluate here the complementary relations between different organizational practices by exploring the factors determining the introduction of different practices of organizational innovation, conditional on a set of observable characteristics related to the firms. We thus perform a multivariate probit model that includes four equations estimating the four organizational practices. This method enables us to investigate the correlation between organizational practices conditional on a set of explanatory variables.

The results of the multivariate probit model for the complete sample of 568 observations are presented in Table B1. From this estimation, the conditional pairwise correlations among the residuals of the four practices were computed (Table B2).

Note that, after controlling for firm-specific effects, the correlation coefficients are positive and highly significant. These results are quite similar for unconditional correlations between the four practices (see Table B3). The correlation coefficient is particularly high between "business practices" and "knowledge management" and between "workplace organization" and "knowledge management". Overall, the adoption approach therefore provides some suggestive evidence of complementarity between the four considered organizational practices. 
Table B1: Results of the multivariate probit model for organizational practices

\begin{tabular}{|c|c|c|c|c|}
\hline & $\begin{array}{l}\text { Business } \\
\text { practices }\end{array}$ & $\begin{array}{l}\text { Knowledge } \\
\text { manageme }\end{array}$ & $\begin{array}{c}\text { Workplace } \\
\text { organization }\end{array}$ & $\begin{array}{l}\text { External } \\
\text { relations }\end{array}$ \\
\hline Intensity of competition & $0.131 *$ & $0.201 * *$ & 0.096 & $0.144 *$ \\
\hline Size & $\begin{array}{c}(0.078) \\
0.249 * * *\end{array}$ & $\begin{array}{c}(0.080) \\
0.153 * * *\end{array}$ & $\begin{array}{c}(0.074) \\
0.185 * * *\end{array}$ & $\begin{array}{c}(0.086) \\
0.169 * * *\end{array}$ \\
\hline Belonging to Luxembourgish group & $\begin{array}{c}(0.051) \\
0.250\end{array}$ & $\begin{array}{l}(0.048) \\
0.351^{* *}\end{array}$ & $\begin{array}{l}(0.049) \\
-0.028\end{array}$ & $\begin{array}{l}(0.051) \\
0.235\end{array}$ \\
\hline Belonging to European group & $\begin{array}{c}(0.163) \\
0.049\end{array}$ & $\begin{array}{c}(0.161) \\
0.064\end{array}$ & $\begin{array}{c}(0.160) \\
0.053\end{array}$ & $\begin{array}{l}(0.168) \\
-0.029\end{array}$ \\
\hline Belonging to other countries group & $\begin{array}{c}(0.148) \\
0.108\end{array}$ & $\begin{array}{c}(0.148) \\
0.212\end{array}$ & $\begin{array}{c}(0.142) \\
0.229\end{array}$ & $\begin{array}{l}(0.157) \\
-0.256\end{array}$ \\
\hline High and medium high technology industry & $\begin{array}{l}(0.206) \\
-0.007\end{array}$ & $\begin{array}{l}(0.203) \\
-0.279\end{array}$ & $\begin{array}{l}(0.201) \\
-0.010\end{array}$ & $\begin{array}{l}0.228 \\
0.259\end{array}$ \\
\hline Medium technology industry & $\begin{array}{l}(0.228) \\
-0.159\end{array}$ & $\begin{array}{l}(0.229) \\
-0.378^{*}\end{array}$ & $\begin{array}{l}(0.219) \\
-0.207\end{array}$ & $\begin{array}{l}(0.236) \\
-0.371\end{array}$ \\
\hline Low technology industry & $\begin{array}{l}(0.9 .17 \\
0.070\end{array}$ & $\begin{array}{c}0.2 .11 \\
-0.210\end{array}$ & $\begin{array}{c}(0.207) \\
0.137\end{array}$ & $\begin{array}{l}(0.947) \\
-0.155\end{array}$ \\
\hline Transport and communication & $\begin{array}{c}(0.227) \\
-0.433 * *\end{array}$ & $\begin{array}{c}(0.227) \\
-0.420 * *\end{array}$ & $\begin{array}{l}(0.218) \\
-0.362 *\end{array}$ & $\begin{array}{l}(0.246) \\
-0.076\end{array}$ \\
\hline Financial intermediations & $\begin{array}{c}(0.203) \\
0.127\end{array}$ & $\begin{array}{c}(0.201) \\
0.046\end{array}$ & $\begin{array}{c}(0.194) \\
0.026\end{array}$ & $\begin{array}{c}(0.216) \\
0.116\end{array}$ \\
\hline Computer activities & $\begin{array}{c}(0.220) \\
0.329\end{array}$ & $\begin{array}{l}(0.216) \\
0.566^{* *}\end{array}$ & $\begin{array}{c}(0.212) \\
0.046\end{array}$ & $\begin{array}{c}(0.232) \\
0.365\end{array}$ \\
\hline $\mathrm{R} \& \mathrm{D}$ - engineering activities and & $\begin{array}{c}(0.242) \\
0.177\end{array}$ & $\begin{array}{c}(0.243) \\
0.116\end{array}$ & $\begin{array}{l}(0.237) \\
-0.046\end{array}$ & $\begin{array}{c}(0.260) \\
0.115\end{array}$ \\
\hline $\begin{array}{l}\text { consultancv } \\
\text { Intercept }\end{array}$ & $\begin{array}{c}(0.245) \\
-1.669 * * *\end{array}$ & $\begin{array}{c}(0.247) \\
-1.723 * * *\end{array}$ & $\begin{array}{c}(0.244) \\
-1.259 * * *\end{array}$ & $\begin{array}{c}(0.270) \\
-2.017 * * *\end{array}$ \\
\hline $\begin{array}{l}\text { Observation } \\
\text { Log likelihood } \\
\text { Wald } \chi^{2}(48)\end{array}$ & \multicolumn{4}{|c|}{-1132.25} \\
\hline
\end{tabular}

Notes: *,** and *** denote significance at the levels of $10 \%, 5 \%$ and $1 \% . p$-values are in parentheses.

Table B2: Conditional correlations between organizational practices

\begin{tabular}{lllll}
\hline \hline & Business practices & \multicolumn{1}{c}{$\begin{array}{c}\text { Knowledge } \\
\text { management }\end{array}$} & $\begin{array}{c}\text { Workplace } \\
\text { organization }\end{array}$ & $\begin{array}{c}\text { External } \\
\text { relations }\end{array}$ \\
\hline Business practices & 1.000 & & & \\
Knowledge management & $0.730^{* * *}$ & 1.000 & & \\
Workplace organization & $0.661^{* * *}$ & $0.730^{* * *}$ & 1.000 & 1.000 \\
External relations & $0.523^{* * *}$ & $0.520^{* * *}$ & $0.601^{* * *}$ & \\
\hline \hline
\end{tabular}

Table B3: Unconditional pairwise correlations between organizational practices 


\begin{tabular}{lcccc}
\hline \hline & $\begin{array}{c}\text { Business } \\
\text { practices }\end{array}$ & $\begin{array}{c}\text { Knowledge } \\
\text { management }\end{array}$ & $\begin{array}{c}\text { Workplace } \\
\text { organization }\end{array}$ & $\begin{array}{c}\text { External } \\
\text { relations }\end{array}$ \\
\hline Business practices & 1.00 & 1.00 & & \\
Knowledge management & 0.54 & 0.48 & 1.00 & \\
Workplace organization & 0.47 & 0.26 & 0.35 & 1.00 \\
External relations & 0.32 & & \\
\hline \hline
\end{tabular}

